\title{
Expectativas e sentimentos de mulheres que esperam por tratamento de reprodução humana*
}

\section{I ${ }^{1}$ Claudia Valença Fontenele, ${ }^{2}$ Ana Cristina D'Andretta Tanaka I}

Resumo: Trata-se de pesquisa qualitativa com o objetivo de verificar as opiniōes, as emoções e os sentimentos de mulheres laqueadas acerca da expectativa pelo tratamento de reprodução humana assistida num ambulatório especializado. As entrevistas foram realizadas em um hospital da rede pública de saúde, na Região Sudeste do Brasil, São Paulo, com 16 mulheres esterilizadas. Como resultados, as seguintes temáticas foram as mais frequentes: ansiedade, assombro do tempo e "des-atenção" dos profissionais de saúde, que foram vivenciados nos momentos em que os sentimentos de solidão e abandono se mostraram mais agudos sob a perspectiva das mulheres. Do estudo emerge a necessidade de se pensar estratégias de atenção e cuidado junto a essa população específica no campo da saúde, visando melhorar seu conforto emocional por meio de um diálogo franco entre mulheres e profissionais de saúde.

> Palavras-chave: reprodução humana assistida; sentimentos; emoções; saúde da mulher.

\author{
1 Doutora em Saúde Pública \\ pela Faculdade de Saúde \\ Pública da Universidade de \\ São Paulo (FSP-USP). Endereço \\ eletrônico: claudiafontenele@ \\ gmail.com \\ 2 Professora titular do \\ Departamento de Saúde \\ Materno-Infantil da FSP-USP. \\ Endereço eletrônico: acdatana@ \\ usp.br
}

Recebido em: 19/08/2012 Aprovado em: 22/02/2013.

\footnotetext{
* Recorte da pesquisa: "Quando nasce um bebê, nasce também uma mãe?" - maternidade e reprodução humana assistida em mulheres laqueadas, financiada pelo Conselho Nacional Científico e Tecnológico (CNPq) e que resultou na tese de doutorado.
} 
A maternidade ainda é uma arena delicada de estudos nos mais diversos campos do saber (KITZINGER, 1996). Na década de 1980, Badinter (1980) colocou em relevo a discussão sobre a maternidade: em resumo, questionava e colocava na berlinda o fato de o amor das mães ser ou não inato. Para a autora, dois fatores estariam ligados à formação do que ela chama, na obra, mito do amor materno: a necessidade de garantia da sobrevivência de sua descendência e a idealização da figura da mãe. Ela chegou à conclusão de que o amor materno não era instintivo, porque ele nasceria da convivência, de conhecer paulatinamente o outro, sendo, portanto, um amor conquistado.

Desde então, a maternidade voltou a ser foco de debates, e atualmente adquiriu novas nuances, como as modalidades de gravidez com útero de substituição, gravidez com material de outras pessoas da família ou, ainda, como a possibilidade de engravidar em períodos chamados de "tardios", entre outros. ${ }^{1}$ Para Fontenele (2010), a maternidade, além de ser um marco especial na vida das mulheres, possui uma significação ambígua. Na esteira dessa temática, a reprodução humana assistida (RHA) consiste na intervenção da ciência no processo de procriação. Seu principal objetivo é tornar possível que pessoas com problemas de infertilidade e esterilidade possam satisfazer o desejo de alcançar a maternidade.

Apesar de constituir um campo de conhecimentos relativamente recente (a primeira tentativa bem-sucedida, com humanos, data do ano de 1978), ganhou larga expansão no contexto brasileiro (DENTILLO, 2012), sobretudo no início do século XXI. Junto a essa expansão, os tratamentos oferecidos pelas novas tecnologias reprodutivas saíram dos discretos consultórios especializados em esterilidade para ganhar manchetes de revistas semanais ou páginas dos jornais dedicados às últimas novidades no campo da saúde. ${ }^{2}$

A "popularização" da RHA, somada às facilidades encontradas nos consultórios médicos, acrescida ainda pela Portaria n. 426/GM, de 22 de março de 2005, ${ }^{3}$ que viabilizou os tratamentos pelo Sistema Único de Saúde (SUS), acabou encorajando casais dos mais diversos segmentos sociais a buscar tratamentos especializados. Esse fenômeno pode ser observado tanto em clínicas do setor privado, quanto nos hospitais da rede pública de saúde. 
Especificamente nos serviços do SUS, tem-se constatado, sobretudo a partir dos anos 2000, uma demanda crescente e que está além das capacidades desse setor e do que pode ser oferecido nos diversos procedimentos de tratamento com a ajuda da RHA (FONTENELE, 2010). Um dos procedimentos da RHA é a fecundação in vitro (FIV), que consiste na fertilização do ovócito pelo espermatozóide em ambiente laboratorial, podendo assim obter pré-embriōes que serão, posteriormente, colocados na cavidade uterina (OLMOS, 2003; OSIS et al., 2003; LUDWIG et al., 1999; MOURA et al., 1999).

Para a realização da FIV pelo SUS, há a necessidade de inscrição nos diversos programas de hospitais que fazem esse tipo de procedimento. Especificamente no hospital onde foi desenvolvida esta pequisa, o trâmite entre efetuar a inscrição e o início do tratamento é demorado. Disso resultam longas filas de espera por um único ciclo de FIV, por exemplo, que podem durar vários anos (FONTENELE, 2010).

Qual o efeito da espera solitária e silenciosa nas mulheres que buscam esse tipo de tratamento? Que tipo de atenção lhes é dada pelos profissionais de saúde do hospital entre apresentação dos exames, diagnóstico e o início efetivo dos procedimentos para realização da FIV?

Sensível a um cotidiano que expõe uma problemática que carece de investigação e compreensão, o objetivo deste estudo foi verificar as opiniōes, as emoçôes e os sentimentos das mulheres acerca da expectativa pelo tratamento de RHA; e ainda, quais são suas percepções acerca do cuidado e do conforto no período de espera pelo primeiro ciclo do tratamento de FIV.

\section{Metodologia}

Optou-se pelo método de investigação qualitativa do tipo descritiva e analítica para a realização da pesquisa (MINAYO, 2000). Esse método permite compreender em detalhes os significados, percepçôes e entendimento dos sujeitos investigados acerca de cada contexto que vivenciam cotidianamente.

O estudo foi realizado numa instituição da rede pública de saúde do Estado de São Paulo, Brasil. Constituíram a pesquisa 16 mulheres inscritas no protocolo de reprodução humana assistida dessa instituição, que é inteiramente financiado pelo SUS. Antes do início do estudo, foi obtido o consentimento 
formal da instituição, no que diz respeito aos aspectos éticos. O projeto foi aprovado pelo Comitê de Ética em Pesquisa da Faculdade de Saúde Pública/USP (PROTOCOLO n 1.780) e pelo Comitê de Ética do hospital As participantes tinham idades entre 30 e 45 anos e aceitaram participar do estudo assinando o termo de consentimento livre e esclarecido, de acordo com as recomendações da Resolução no 196/96 do Conselho Nacional de Saúde.

Todas as mulheres entrevistadas eram casadas e laqueadas; todas haviam passado pela triagem de exames e diagnóstico e estavam aguardando a convocação para darem início ao primeiro ciclo da FIV. Ao fazer o recorte metodológico, optou-se por trabalhar apenas com mulheres esterilizadas, a partir da constatação da alta demanda desse segmento na busca por tratamentos de reprodução humana assistida. Quando foi feita a investigação nos prontuários das pacientes, verificou-se que todas haviam tentado fazer a reanastomose tubária sem sucesso, restando-lhes como única alternativa um tratamento de alta complexidade, como é o caso da FIV.

Entre elas, oito cursaram o ensino médio; sete cursaram o ensino fundamental (destas, seis não chegaram a concluí-lo) e uma chegou a iniciar a faculdade de Direito, mas não terminou a formação. No que diz respeito ao exercício de uma atividade remunerada, todas trabalhavam com registro, exceto duas que se autointitularam "donas de casa". As ocupações exercidas eram: camareira, corretora, cabeleireira, domésticas, secretárias e vendedoras.

O material empírico foi colhido por meio de observação participante, grupo de discussão e entrevistas abertas, cujas questôes norteadoras foram: "quais são seus sentimentos em relação à espera pelo tratamento? Como se sentem durante o período de espera pelo tratamento? Que apoio ou suporte lhes é oferecido? O que fazem para atenuar a angústia que o tratamento em si suscita?”. As entrevistas eram agendadas e realizadas individualmente, de acordo com a disponibilidade e horário estabelecido pelas entrevistadas. As observações se deram durante todo o período da pesquisa no hospital. Houve um encontro para o grupo de discussão, no qual mulheres na mesma situação - esterilizadas e em busca de uma gravidez - puderam partilhar as impressóes sobre todo percurso que cada uma delas fez até aquele momento. As entrevistas foram gravadas e, posteriormente, transcritas.

A partir das informações das mulheres, realizou-se análise temática dos conteúdos. A compreensão delas, de suas emoções, dos tipos de conexôes 
observadas nas relações de força dos agentes sociais e a dissimulação de poder nas relações simbólicas no cotidiano foram circunscrevendo de que forma estes afetaram seu conforto e bem-estar. E para preservar a identidade das participantes, optou-se por utilizar nomes de flores, uma vez que a trajetória dessas mulheres tem beleza, força, assim como espinhos e ameaças no caminho.

Este estudo pretende contribuir para o desenvolvimento de novas pesquisas no campo do cuidado e conforto emocional à mulher, questôes que devem ser vistas com maior senso crítico, ações que precisam ser reavaliadas e outras tantas atitudes, ainda, que precisam ser abandonadas (consultas meramente técnicas, onde impera um ambiente frio e onde a subjetividade das mulheres muitas vezes não é levada em consideração).

É válido registrar que a pesquisa possui a limitação de ser pontual, sem acompanhamento das mulheres por um tempo mais prolongado. Embora apresentando esse viés metodológico, o estudo sugere a necessidade de novas pesquisas que tenham como objetivo produzir conhecimento acerca do cuidado e do conforto emocional da mulher que busca uma gravidez por intermédio de novas tecnologias reprodutivas. Seria importante, na mesma medida, contribuir em termos de produção de conhecimento aos profissionais de saúde que atuam nesse setor específico dos serviços de saúde, para que se possa, ainda, respeitar as mulheres que são cuidadas, independentemente da classe social, educação, origem, credo e outras diferenças culturais.

\section{Resultado e discussão}

A partir do tratamento e análise do material empírico, surgiram temáticas concernentes aos discursos das mulheres, entre as quais se destacam: ansiedade e tempo longo de espera; o assombro do tempo e a "des-atenção" dos profissionais de saúde em relação a elas enquanto esperam pelo tratamento.

\section{Ansiedade e tempo longo de espera}

O desejo de nova maternidade amadurece, pouco a pouco, após algum tempo de casamento, entre as mulheres entrevistadas. Quando tomam conhecimento da RHA, empreendem busca de locais para execução dos tratamentos: "É muito lindo ser mãe... É uma coisa que não tem nem explicação. E eu tô querendo isso há muito tempo" (Acácia). 
Partindo das unidades básicas de saúde (UBS) de diversos - e às vezes, longínquos - bairros, onde verbalizam pela primeira vez o desejo de gravidez, rumo à região central da cidade de São Paulo - onde está localizado um serviço de RHA totalmente custeado pelo SUS, as mulheres, provenientes até mesmo de outros municípios do estado, passam a receber de desconhecidos os cuidados iniciais para o tratamento, tais como: anamnese, aferição de pressão, peso, entre outros, além da solicitação de alguns exames mais gerais. Esses procedimentos visam verificar o estado de saúde como um todo do casal. Desde o início, com endereço, ambiente e linguagem diferentes, estabelece-se uma nova situação de interação, diferente dos encontros cotidianos a que estão habituadas quando procuram o serviço médico nas proximidades de suas residências. E esse primeiro estranhamento foi percebido como fator propiciador de uma inibição inicial e, igualmente, preponderante, no silenciamento delas nos momentos de consulta.

Ah, eu também não consigo falar nada. Meu médico é um baixinho e ele tem uma cara de bravo, de que tá sempre com pressa, então eu nem abri a boca na hora da consulta. (Dália).

Nunca perguntei isso. Nunca me preocupei com isso [detalhar o tratamento de RHA]. Também nunca quis incomodar o médico que me atende, que ele é meio nervoso, deve ser muito ocupado e não quero ficar enchendo ele de pergunta pra não atrapalhar, sabe? (Camélia).

Muitas das dúvidas ou perguntas de foro mais íntimo, inquietações, ficavam relegadas ao segundo plano, uma vez que viabilizar a gravidez era emergencial para todas elas. As incertezas e questionamentos pareciam menores frente aos medicamentos a serem administrados, que poderiam tornar realidade o sonho da nova maternidade.

Percebeu-se neste estudo que ainda que não possuam contatos mais estreitos com os profissionais de saúde das UBS, este é um local conhecido, onde elas sentem que de algum modo a instituição de saúde lhes pertence, diferentemente do que ocorre com o hospital. A partir da apropriação simbólica da UBS que elas relataram, sentem que podem agir com maior desenvoltura na busca por ajuda em quadros das pequenas patologias correntes, bem como no trato com os profissionais de saúde que ali estão para atendê-las.

A pesquisa deslindou o fato de que a relação dessas mulheres com a equipe de saúde tanto do posto (numa medida, narrada por elas, como mais atenuada), quanto do ambulatório especializado (mais distante, indiferente, seco) tem início 
sob o signo de um poder pouco visível, mas muito sentido: o simbólico. Este “[...] é um poder que aquele que lhe está sujeito dá àquele que o exerce, um crédito com que ele o credita, que ele lhe confia pondo nele a sua confiança" (BOURDIEU, 1989, p. 188). Por isso, a relação que a mulher possui frente ao saber médico é de submissão no momento que expressa sua insatisfação com a organização familiar e demanda ajuda para fazer um tratamento que resultará num bebê. Há a percepção, por parte dessas mulheres, de que o médico tem um poder: ele pode efetivar um tratamento que resultará na gravidez que, em última instância, legitimará seu casamento. E este poder é, ao mesmo tempo, simbólica e socialmente legitimado. A mulher fica, assim, numa situação um tanto delicada, não apenas para questioná-lo frente ao que acontecerá em seu corpo (TAMANINI; PARZIANELLO, 2009), como também para expor suas inseguranças e dúvidas.

Sendo assim, logo que são introduzidas no ambiente hospitalar, asséptico e desconhecido, as mulheres relataram sentir, desde o primeiro dia, certo "respeito obediente” em relação aos profissionais de saúde: eles detêm, imaginária e socialmente, o poder do conhecimento que irá proporcionar a elas a gravidez desejada (e até aquele momento mantida sob o signo de "sonho"). Portanto, o poder de conseguir impor legitimamente significações (o saber médico) e de ocultar as relações de força existentes (a mulher está ali apenas para aquiescer e colaborar) constitui um modo de exercício de violência simbólica, cuja magnitude vai depender da equipe de profissionais de saúde que atua no serviço.

[...] ela [a ginecologista] me falou que ia me ajudar, ela era muito boazinha, essa médica, falou que ia conversar com a assistente social, que ia ver o que podia fazer por mim. Nossa! Eu nem dormi nesse dia. Você sabe que nem todo médico é assim, né? Tem uns que nem olham na cara da gente... (Íris).

Outro aspecto revelado neste estudo foi a ansiedade e o tempo longo de espera. Ambos emergem nos discursos das mulheres, que passaram por todo o processo de triagem no ambulatório de reprodução humana e receberam um número que representa o lugar delas na fila de espera. Todas, de um ou outro modo, deram ênfase à grande inquietude, mesmo angústia, que é aguardar o telefone tocar informando que chegou sua vez de iniciar o tratamento. Igualmente, a sensação de longo tempo, ou seja, ainda que três anos tenham se passado de fato, e elas mesmas avaliem esse período como relativamente curto, a sensação interna, o sentimento afetivo em relação a essa espera é o de que muito mais tempo se passou. 
Agora tô na fila daqui, esperando, esperando e esperando [...]. (Dália).

Esse tempo que a gente espera é muito ruim, então a gente tem que fazer alguma coisa, senão a ansiedade acaba com a gente. A gente sonha e quer muito o bebê, então tem que ter paciência, calma e é difícil que a gente sabe, mas sente. (Flora).

Às vezes eu pensava: eu não vou conseguir, acho que eu não vou conseguir, acho que eu vou desistir. (Acácia).

Uma das mulheres colocou em relevo de modo mais contundente a dor emocional da espera:

O difícil, quer dizer, o doloroso nisso de ter filho de novo é ter que esperar... Essa fila é muito longa, vai demorar mais de ano pra gente começar a fazer o tratamento. Se desse pra ser mais rápido, seria o ideal. O que a gente faz enquanto espera? É de dar nos nervos. (Hortênsia).

Algumas relataram momentos dramáticos, em que a dor da espera parecia fatigar as forças que ela mesma, e alguns familiares e amigos, sempre sustentaram na empreitada:

Estamos esperando esse bebê e sei que é demorado, mas está sendo mais demorado de sentir, sabe como? Olhando o tempo parece que tem poucos meses, mas no meu coração tem muito tempo. Queremos nosso filho logo. (Gardênia).

O meu caso é... Quando eu conseguir engravidar, a criança vai ser mais amada do que as outras duas gravidezes que eu tive. Porque eu amo de verdade o meu marido e é um sonho que a gente tem de ter esse filho. Vai ser mais desejado, mais esperado do que os outros que eu já tive [começa a chorar]. (Dália).

Porque eu vejo assim: a hora que meu filho vai chegar em casa e que meu marido vai ser pai. Porque pra mim é assim: será que hoje eu vou engravidar? Mesmo sabendo que não vai ser agora, né? Que vai demorar. Mas é sempre esperando ali, será que hoje vai me ligar [o hospital]? (Margarida).

Todo discurso dessas mulheres colocou em relevo a necessidade de apoio, e não apenas no âmbito familiar. Seria interessante que dentro do próprio ambulatório existisse um serviço, um setor, comprometido com o cuidado, conforto e sentimento de segurança dessas mulheres que se submeterão aos tratamentos de FIV. Ter uma equipe de apoio presente, conversando com elas, ouvindo-as em seus relatos de angústia emocional, medos e anseios, ainda que pareçam ações simples, de fato representaria efetivamente uma ação mais voltada ao conforto emocional.

Esse apoio emocional à mulher poderia tornar o tratamento menos tenso, mais "palatável", sobretudo no que diz respeito ao enfrentamento dos efeitos adversos dos medicamentos, bastante desagradáveis, como irritabilidade, 
alteração do humor, náuseas, dores de cabeça, entre outros (BASILE et al., 2007;

EMPERAIRE, 2006). Esse apoio também pode colaborar para que a experiência no tratamento da reprodução humana assistida tenha um significado mais positivo na vida delas, uma vez que as taxas de sucesso desse tipo de procedimento ainda são relativamente baixas (REIS et al., 2006; BASILE et al., 2007) e pioram com o aumento da idade, ou seja, justamente com a passagem do tempo.

Outro fator que poderia contribuir para o conforto dessas mulheres seriam orientações e informações que poderiam ser dadas sobre o desenvolvimento do trabalho, os passos e futuros encaminhamentos. Esse tipo de cuidado poderia evitar não apenas os ruídos de comunicação, como também minimizaria o impacto que as crenças e boatos têm sobre o tratamento; poderia evitar que estes não alcançassem uma proporção de verdade, tal qual aconteceu com Acácia, que passou anos laqueada, sem procurar ajuda, imaginando que poderia, de algum modo, ficar grávida:

Eu não tinha consciência [que a laqueadura era o mesmo que esterilização, que era definitiva] porque eu fiquei aguardando durante sete anos para ver se eu ainda ia engravidar novamente.

Semelhante fato ocorreu com Íris:

Quando eu descobri que, tipo assim, eu me imaginava, até um tempo desse [até pouco tempo atrás], eu imaginava que... que aquilo [a laqueadura] não ia atrapalhar [a concepção]. Porque eu ia engravidar, sim, porque Deus ia fazer com que eu engravidasse, tendo trompas ou não. Aí cheguei ficar meses sem menstruar e tudo mais, achando que tava grávida e não tava grávida.

Mesmo o contato físico pode representar um fator de conforto: a transmissão da mensagem de apoio ao tocar os ombros da mulher, por exemplo, incentivando-a a ter coragem e força para lidar com os percalços da espera poderiam ser muito tranquilizadores:

Não é todo mundo não, mas tem uma doutora aqui, uma loirinha, ela é nova, ela é muito boa, me dá forças. Mesmo quando estou fraca, ela me dá forças. Sei que é porque ela é novinha, está só começando, mas mesmo assim, ela pega na gente, diz que é pra gente ter calma. Fico mais tranquila e acho que vai dar certo sim. (Deise - grifos nossos).

Quando o profissional se sensibiliza com a situação vivenciada pela mulher laqueada, se sente implicado no processo do tratamento, propicia um ambiente de cuidado e conforto, por meio de gestos, palavras, que favorecem maior proximidade entre a mulher e a equipe de saúde. Um diálogo aberto, no qual a 
mulher possa se expressar livremente, se sentir apoiada e segura, é uma forma de promoção da saúde.

\section{Assombro do tempo}

O tempo, especificamente no que diz respeito à idade das mulheres em relação às chances de conseguir uma gravidez, era outra temática constante em seus discursos. Havia a ideia difundida de que, quanto mais velhas, menores seriam as chances de sucesso do tratamento, fato corroborado pela literatura especializada (REIS et al., 2006). Nesse sentido havia, igualmente, certa rejeição ao que elas denominaram "mãe-avó", entre outros.

Eu quero muito mais ser mãe de novo. Dois [filhos] é pouco. Minha meta é de ser mãe, mais uma vez, mais duas vezes. Se for possível porque é tão difícil, viu? Tá lá no 2570 [número de registro na fila de espera pelo tratamento] que tá tão difícil. Tá tão lenta a fila! E eu não quero ser mãe-vó, né? Quero curtir meus pequenos. E essa demora toda! (Magnólia).

Quando uma equipe de saúde orienta as mulheres a respeito do cuidado e do conforto, especialmente o emocional, explicitando como serão as etapas do tratamento, deixando espaços para perguntas, para a dissolução das dúvidas, ela proporciona um ambiente mais relaxado.

Esse tipo de ação, no ambiente hospitalar, é fundamental porque a questão da "passagem do tempo" foi muito citada, e diversas vezes repetida. Neste estudo, elas demarcaram bastante bem, e com muita aflição, o tempo. Para elas, o relógio é um inimigo no campo de batalha que precisa ser derrotado.

Aqui nesse grupo [entre as mulheres que esperam pelo tratamento] não tem quem não esteja ansiosa, querendo fazer logo esse tratamento. Mas essa ansiedade é de querer ver logo a barriga crescer de novo, passar por tudo aquilo de novo. E como dizem que o tempo conta, que o relógio trabalha contra nós, queremos que o nosso telefone toque logo dizendo pra gente ir ao hospital fazer o bebê. (Jasmim).

Eu tô correndo atrás disso. Mas não posso perder muito tempo, pois já estou com 38 anos e o médico falou que quanto mais velha, mais difícil de conseguir ter o filho. (Gardênia).

Nós dois velhos? Ah não! Quero ter logo esse filho pra não ficar só eu e ele [o marido], nós dois velhos dentro de casa. (Violeta).

Em seus discursos, as mulheres aliam a ansiedade ao tempo que passa, ao tempo que pode ser perdido e precisa urgentemente ser aproveitado. Elas anseiam a celeridade no procedimento apesar de terem ingressado num serviço de alta 
demanda, e desde o começo terem conhecimento desse fato. Também têm o conhecimento de que essa demanda existe especificamente pela facilidade de ter todo tratamento financiado pelo SUS.

Pra eu ligar, por exemplo, como hoje, eu peguei o número do telefone numa segunda-feira e o dia de telefonar era quarta-feira. Então, em orelhão fica mais difícil, né? E... não consegui. Quando eu consegui falar o rapaz que me atendeu falou pra mim que tinha mudado o número. Quando foi no mês seguinte, eu tentei. (Petúnia).

Uma vez atendidas, elas tinham imaginado que o início do tratamento iria demorar, mas não tinham conhecimento da grandeza e da abrangência do tempo: mais de três anos. E a vivência real da espera, cotidiana, torna a experiência crescentemente mais dolorosa.

A ansiedade é tamanha! A ansiedade é muito grande. [...] você fica lá naquela agonia. Porque é uma agonia aquilo. E o dia passa [lentamente], a hora passa [...] (Maria Flor).

Tira o fantasma, entendeu? [se um profissional pudesse dar maiores informações] Se tivesse alguém lá pra tirar nossas dúvidas, pra ajudar a gente, ia ajudar até nas frustrações. Te ajuda muito. Porque esse negócio de esperar não é pra qualquer um não! Tem que ter estrutura, tem que ser forte, senão você não aguenta. (Rosa).

A ansiedade, a minha dúvida, a partir do que é que vai acontecer. Desde então eu saberia, até hoje eu só peguei procedimento de exames. A partir de agora eu não sei o que é que vai acontecer. (Perpétua).

E eu tô muito ansiosa para esse dia chegar logo, quero ver minha barriga crescer de novo, quero dar esse filho para ele, quero cuidar, fico imaginando tudo isso. Eu sonho, sonho muito. (Íris).

É possível que, se houvesse um atendimento específico, paralelo ao da RHA, que oferecesse apoio às mulheres da fila de espera, o peso do tempo fosse minimizado. A solidão sentida por elas, a sensação de não estar sendo cuidada, de não ter ideia ou noção do próximo passo a ser dado no tratamento, os silêncios que marcam as consultas, condutas e mesmo aplicação dos medicamentos, suscitam na mulher um sentimento de não-cuidado, de não-conforto - enfim, de isolamento.

Faço tudo direito para dar certo, para não atrapalhar, ainda mais aqui que sei que é um grande hospital, não quero que nada dê errado. E também quando tô com o médico procuro ficar quietinha. Principalmente com os mal-humorados [risos]. (Jasmim).

Não, não informaram nada [sobre a medicação prescrita]. Nada, nada, nada. Só passaram a receita, "toma tantas injeçôes, vai tomando, vamos fazer o exame". O que ele explicou é que a injeção era para ovular. E quando a enfermeira aplicou... Ai, ai, vi todas as estrelas. Que mão pesada! (Deise).

Mas eu tô nisso só, só eu e Deus. Me sinto muito sozinha. (Violeta) 


\section{Considerações finais}

No contexto das mulheres que participaram do presente estudo, buscar um hospital para realizar o desejo de nova gravidez representa, para elas, uma ação corajosa. Uma decisão permeada de conflitos, que vem sendo amadurecida há muito, bem antes de se transformar no ato concreto de entrar no hospital e explicitar a demanda. E, ao entrar no hospital, a mulher percebe a pouca ou nenhuma familiaridade com o ambiente em que está sendo cuidada: não é mais o posto de saúde sabido e reconhecido, mas outro, distante, com fluxos, códigos e nuances que precisarão ser aprendidos. Além disso, a equipe dos profissionais de saúde é composta por desconhecidos, pessoas às quais são imputados saberes e que transmitem diretivas à mulher, suscitando, na maior parte das vezes, um sentimento de timidez que a imobiliza, impedindo-a de expor as dúvidas quanto ao tratamento ou, eventualmente, de compartilhar seus sentimentos que em momentos alternados podem ser de medo, desesperança. Quando o profissional no campo da saúde deixa de abrir esse espaço, ou deixa de perceber essas nuances na consulta, propicia um não-apropriamento, por parte da mulher, do momento que vivencia, de busca de uma gravidez, momento esse que é tão frágil. Além disso, há a questão complementar da solidão, tendo em vista que na maioria das consultas, a mulher comparece sozinha. ${ }^{5}$

No âmbito do cuidado e do conforto da mulher, ainda no espaço do serviço de saúde, percebeu-se nesta pesquisa que há um desconhecimento sobre a necessidade de conceder-lhe melhor amparo. $\mathrm{O}$ conforto emocional dessas mulheres é muito importante no andamento e encaminhamento do tratamento, tal como ocorre em outros eventos no campo da saúde. Constatou-se que quando a mulher se sente tratada como "mais uma" na rotina do ambulatório de RHA, sente que suas necessidades e sua singularidade são desconsideradas pela equipe de saúde. Alguns relatos dão conta de profissionais estressados, mal-humorados e indiferentes. Esse fato, por si só, representa um desrespeito à mulher.

A presente pesquisa traz para a arena da discussão acadêmica e das políticas no campo da saúde pública as visões de mundo de mulheres a respeito do cuidado e do conforto, suas emoções, no exato momento em que estão à espera de um tratamento de RHA. E todo material empírico mostrou que há necessidade de reflexão e mudança de postura por parte dos profissionais de saúde e da organização dos serviços de saúde. Há a necessidade de se criar um atendimento 
que possa dar respaldo emocional a essas mulheres, que se mostraram tão debilitadas pelos anos de espera e por lidar cotidianamente com a angústia da incerteza: "E se eu não tiver mais idade para fazer esse tratamento?", indagava Deise, em vários momentos durante a entrevista, expressando seu temor frente ao tempo que possui e que avalia como um tanto restrito.

As mudanças e dificuldades na vida dessas mulheres, em função da gravidez que almejam, produzem sentimentos que geram modificaçóes em sua autoestima e nas próprias relações sociais que estabelecem. O desejo pelo bebê passa a ocupar a maior parte de seus pensamentos e inquietudes. E essa experiência poderia ser menos traumática se, gradualmente, houvesse apoio de profissionais de saúde, se estes passassem a levar em consideração os aspectos psicossociais da mulher.

Para que isso ocorra, a assistência deveria também ter como um de seus enfoques o período de espera pelo tratamento de RHA, quando ela fica em casa aguardando o telefone tocar, imbuída de um sentimento de expectante solidão. Ela precisa de um acompanhamento ou, pelo menos, da oferta de apoio profissional. O que precisa ganhar maior destaque nesse campo de tratamento é justamente o modo de lidar com os sentimentos, angústias, emoções e dificuldades que essas mulheres vivenciam, e não apenas os procedimentos técnicos e de coleta de material para manipulação em laboratório.

A mulher, quando busca um serviço especializado para procriar, necessita, e deveria receber, um cuidado eficiente e seguro, garantindo-lhe os benefícios dos avanços científicos, não obstante permitindo-lhe o exercício da cidadania, contribuindo para uma futura gravidez mais tranquila e segura diante dos riscos que são próprios desse tipo de tratamento (MIKI et al., 2011; BARRI et al., 2011; DONDORP; de WERT, 2011; TOAFF et al., 1995).

A mudança desse quadro requer, em primeiro lugar, o reconhecimento de que uma atenção apropriada e respeitosa junto à mulher que busca tratamento de RHA é direito seu ${ }^{6}$ e que sua violação é passível de punição. A atenção está essencialmente atrelada ao conforto, os quais são mister para a mulher nesse momento delicado de sua vida. Estes estão relacionados não apenas ao ambiente externo, dos corredores do hospital e do ambulatório, como também ao interior, ou seja, dos profissionais que lidam com essas mulheres e suas emoções. Estas, segundo as mulheres, são muitas vezes conflitantes: desejo, medo, amor, insegurança, entre outros. 
Para oferecer conforto - e não apenas o tratamento, é preciso levar em conta um ambiente em que a mulher se sinta segura e informada; onde possa dialogar. Em outras palavras, omde ela se sinta acolhida de modo respeitoso, mesmo afetivo, sinta proteção e bem-estar. Portanto, além de uma orientação científica adequada, do detalhamento do tratamento de modo global, a mulher carece de conforto emocional. Assim, deve ser considerada em sua totalidade, sendo valorizada em sua singularidade, possibilitando aos profissionais de saúde um modo de ver e agir que priorize um tratamento com distinção nas práticas diárias do atender a mulher de modo mais compreensivo e "humanizado"?

\section{Referências}

ABUSHEIKHA, N.; SALHA, O.; BRINSDEN, P. Extra-uterine pregnancy following assisted conception treatment. Hum Reprod Update, ESHRE, v.9, n.1, p.80-92, 2000.

BADINTER, E. L'amour en plus: histoire de l'amour maternel au XVIIè-XXè siècle. Paris: Flammarion, 1980.

BARRI, P.N. et al. Prevention of prematurity by single embryo transfer. J Perinat Med., v.39, n.3, p.237-240, 2011.

BASILLE, C. et al. En fécondation in vitro (FIV): pourquoi je ne stimule pas? Rev Gynécologie Obstétrique \& Fertilité, v.35, n.9, p.877-880, 2007.

BOURDIEU, P. O poder simbólico. Rio de Janeiro: Bertrand Brasil, 1989.

COLLUCCI, C. Por que a gravidez não vem? São Paulo: Atheneu, 2003.

DENTILLO, D.B. Reprodução humana: cresce demanda por tratamento de infertilidade, mas o acesso ainda é caro e seletivo. Cienc. Cult., v.64, n.4, p. 10-11, 2012.

DONDORP, W. De; WERT, G. Innovative reproductive technologies: risks and responsibilities. Hum Reprod., v.26, n.7, p.1604-1608, 2011.

EMPERAIRE, J.C. Stimulations ovariennes minimales: moins dangereuses et souvent aussi efficaces. Rev Gynécologie Obstétrique \& Fertilité, v.34, n.4, p.354-355, 2006.

FONTENELE, C.V. “Quando nasce um bebê, nasce também uma mãe?": maternidade e reprodução humana assistida em mulheres laqueadas. 2010. 180p. Tese (Doutorado em Saúde Pública) - Faculdade de Saúde Pública, Universidade de São Paulo, São Paulo, 2010.

KITZINGER, S. Mães: um estudo antropológico da maternidade. Lisboa: Presença, 1996. 239p. LUDWIG, M. et al. New aspects of cryopreservation of oocytes and embryos in assisted reproduction and future perspectives. Hum Reprod., v.14, supl 1, p.162-185, 1999.

MIKI, Y. et al. Suppression of estrogen actions in human lung cancer. Mol CellEndrocrinol., v.340, n.2, p.168-174, 2011. 
MINAYO, M.C.S. O desafio do conhecimento: pesquisa qualitativa em saúde. São Paulo: Hucitec, 2000.

MOURA, M.D. Influência do tratamento cirúrgico conservador da hidrossalpinge nos resultados de fertilizaçäoin vitro. RevReprod Clim., v.4, n.2, p.89-94, 1999.

OLMOS, P.E. Quando a cegonha não vem: os recursos da medicina moderna para vencer a infertilidade. São Paulo: Carrenho, 2003.

OSIS, M.J.D. et al. Fertility and reproductive history of sterilized and non-sterilized women in Campinas. Cad Saúde Pública, v.19, n.5, p.1399-1404, 2003.

REIS, R.M. et al. Resultados de fertilização in vitro em mulheres submetidas previamente à laqueadura tubária. Rev Bras Ginecol Obstet., v.28, n.12, p.715-720, 2006.

TAMANINI, M.; PARZIANELLO, D. Da crítica à medicalização tecnológica reprodutiva às tecnologias sem corpo. In: MATOS, M. (Org.). Enfoques feministas e os desafios contemporâneos: diversidade das abordagens e perspectivas nas discussões de gênero. Belo Horizonte: FAFICH/DCP, 2009. p. 155-178.

TOAFF, M.E.; GROSS, S.T.; LEV-TOAFF, A.S. Controlled ovarian hyperstimulation and transvaginal intratubal insemination as an alternative to gamete intrafallopian transfer. FertilSteril, v.64, n.4, p.777-786, 1995.

\section{Notas}

1 Vide: http://revistacrescer.globo.com/Crescer/0,19125,EFC548750-2213,00.html; http://www. rnw.nl/portugues/article/ovulos-no-freezer-para-a-maternidade-tardiaou http://www.clicrbs.com. $\mathrm{br} /$ especial/rs/bem-estar/19,0,3173278,Gravida-aos-54-anos-Solange-Couto-reacende-discussaosobre-maternidade-tardia.html

2 Consultar: http://almanaque.folha.uol.com.br/ciencia_06jul1969.htm; http://veja.abril.com. br/070508/p_140.shtml; http://www.istoe.com.br/reportagens/24363_UM+E+BOM+TRES+E+ DEMAIS+?pathImagens=\&path=\&actualArea=internalPage; http://revistaepoca.globo.com $/$ Revista/Epoca/0,,EMI177011-15257,00.html

${ }^{3}$ Consultar: http://bvsms.saude.gov.br/bvs/publicacoes/portaria_426_ac.htm

${ }^{4}$ Nos momentos de entrevista, essa obediência foi percebida mais como uma atitude servil do que simplesmente acatar decisões e diretivas.

${ }^{5}$ Até por questôes de cunho mais econômico, o casal negocia entre si, quando ambos trabalham, e ela falta o trabalho para as consultas.

${ }^{6}$ Disponível em: http://bvsms.saude.gov.br/bvs/publicacoes/portaria_426_ac.htm

${ }^{7}$ C.V. Fontenele participou da concepção original da pesquisa, da revisão da literatura, da coleta e análise dos dados, da interpretação e discussão dos dados, da organização e da redação do artigo. A.C. d'A. Tanaka participou da concepção do projeto, do planejamento da coleta, colaborou na discussão da análise de dados e participou na redação do artigo científico. 


\section{Expectations and feelings of women awaiting human reproduction treatment}

This paper aimed to investigate the opinions, emotions and feelings of sterilized women awaiting assisted human reproduction treatment in a specialized sector of a public hospital. Sixteen sterilized women were interviewed in the health care department of a public hospital in São Paulo, southeastern Brazil, as to their experiences while they had been awaiting treatment. The feelings referred to were: anxiety, the fear of taking up the time of the health personnel, and fear of their dis-attention, experienced during the moments when the women's feelings of loneliness and abandonment became most acute. It is evident from this study that there is a need to create strategies to guarantee that this specific population in the health field receive adequate attention and care, with a view to ensuring their emotional comfort, through a straightforward dialogue among women and healthcare professionals.

Key words: assisted human reproduction; feelings; emotions; women's health. 